\title{
MUSIUM KAPAL NUSANTARA DI JAKARTA UTARA
}

\author{
Dina Amelia Putri ${ }^{1)}$, Martin Halim ${ }^{2)}$ \\ 1) Program Studi S1 Arsitektur, Fakultas Teknik, Universitas Tarumanagara, emiliayustiana8@gmail.com \\ 2) Program Studi S1 Arsitektur, Fakultas Teknik, Universitas Tarumanagara, martinhalim90@gmail.com
}

\begin{abstract}
Abstrak
Sejarah maritim Indonesia adalah sejarah peradaban manusia secara umum. Peran laut, daratan, pelaut dan kapal tak bisa dilepaskan karena merupakan satu kesatuan pembentuk unsur maritim Indonesia. Kapal merupakan bagian sejarah besar maritim Indonesia, kapal adalah transportasi yang penting di Indonesia mengingat indonesia adalah negara kepulauan terbesar di dunia dengan jumlah 17.504 pulau. Peran kapal sangat penting bagi sejarah dan ekonomi, sosial, budaya Indonesia itu sendiri kapal memiliki nilai sejarah yang sangat kuat bagi Indonesia dan tentu nya masyarakat Indonesia perlu tau dan mengerti sejarah kapal di Indonesia. Namun pengetahuan mengenai perkapalan di Indonesia masih kurang bagi masyarakat awam. Oleh sebab itu salah satu cara untuk menyelesaikan permasalahan tersebut adalah penyediaan sebuah "Museum Kapal Nusantara" sebuah wadah rekreasi yang mengedukasi masyarakat mengenai perkapalan di Indonesia. Terletak disebelah pelabuhan sunda kelapa bangunan seakan menjadi satu kesatuan dengan sejarah besar pelabuhan sunda kelapa dengan disediakan nya aktvitas luar ruang yang berorientasi pada pelabuhan sunda kelapa dimana pengunjung dapat mencoba mendayung perahu dan lainnya. Dalam wadah rekreasi ini disediakan ruangan seperti ruang pamer, area simulator, area audiovisual, cinema 4D, aquarium ikan karang, dan kegiatan pendukung lainnya. Ide-ide tersebut dibungkus dan di tampilkan secara interaktif, Dengan teknologi 2D, 3D dan 4D sebagai wadah penyampaian dalam museum kapal nusantara ini. Dengan dibangunnya proyek ini diharapkan masyarakat Indonesia lebih mengenal perkapalan indonesia dan terinsprasi untuk dapat ambil andil dalam perkembangan industri kapal di Indonesia yang tentunya dapat mewujudkan cita-cita pemerintah menjadikan Indonesia sebagai poros maritim dunia.
\end{abstract}

Kata kunci: interaktif, kapal nusantara, maritim, museum, sejarah, sunda kelapa

\begin{abstract}
Indonesian maritime history is the history of human civilization in general. The role of the sea, land, seafarers and ships cannot be released because it is a unit forming the Indonesian maritime element. Ships are part of Indonesia's great maritime history, ships are an important transportation in Indonesia considering that Indonesia is the largest archipelagic country in the world with 17,504 islands. The role of ships is very important for history and economics, social, Indonesian culture itself ships have a very strong historical value for Indonesia and of course Indonesian people need to know and understand the history of ships in Indonesia. However, knowledge of Indonesian ships in Indonesia is still lacking for ordinary people. Therefore, one way to solve this problem is the provision of a "Nusantara Ship Museum" a recreational place that educates the public about shipping in Indonesia. located next to the port of Sunda Kelapa building as if it were a whole with the great history of the Sunda Kelapa harbor with its outdoor activities oriented to the port of Sunda Kelapa where visitors can try rowing boats, etc. In this recreation place, there are provided spaces such as showrooms, simulator areas, audiovisual areas, $4 D$ cinema, reef fish aquariums, and other supporting activities. These ideas are wrapped and displayed interactively, with $2 D$ and $4 D$ technology for delivery method at this archipelago ship museum. With the construction of this project, it is hoped that the Indonesian people will become more familiar with Indonesian shipping and be inspired to take part in the development of the ship industry in Indonesia, which will be able to realize the government's aspiration to make Indonesia a world maritime axis).
\end{abstract}

Keywords: archipelago ship, history, interactive, maritime, museum, sunda kelapa 


\section{PENDAHULUAN}

\section{Latar Belakang}

Sejarah maritim Indonesia adalah sejarah peradaban manusia secara umum. Peran laut, daratan, pelaut dan kapal tak bisa dilepaskan karena merupakan satu kesatuan pembentuk unsur maritim Indonesia. Kapal merupakan bagian besar sejarah besar maritim Indonesia, kapal adalah transportasi yang penting di Indonesia mengingat indonesia adalah negara kepulauan terbesar di dunia dengan jumlah 17.504 pulau. (Motik, 2007)

\section{Identifikasi Masalah}

Kapal merupakan bagian sejarah besar maritim Indonesia. Peran kapal sangat penting bagi sejarah dan ekonomi, sosial, budaya Indonesia itu sendiri kapal memiliki nilai sejarah yang sangat kuat bagi Indonesia .Namun kenyataannya pengetahuan mengenai perkapalan di Indonesia masih kurang bagi masyarakat awam. Kurang nya pengetahuan dapat disebabkan oleh ketidaktersediaan sarana atau wadah yang menyediakan informasi mengenai perkapalan indonesia dan kurang nya minat masyarakat indonesia itu sendiri untuk mempelajari mengenai perkapalan Indonesia

\section{Tujuan dan Manfaat}

Sebagai tujuan wisata rekreasi yang mengedukasi dengan konsep interaktif mengenai sejarah kapal Nusantara bagi masyarakat Indonesia, terutama para kaum muda, Meningkatkan ketertarikan dan kepedulian masyarakat Indonesia akan sejarah kapal Nusantara. Dengan menyediakan wadah yang berisi wawasan dan pengetahuan mengenai sejarah kapal Nusantara dan perkembangannya yang diharapkan sebagai jembatan untuk menggugah rasa ingin tahu dan ketertarikan masyarakat Indonesia di bidang industri kapal sehingga kedepan nya dapat terlibat dalam perkembangan industri kapal di Indonesia.

\section{METODE}

Penelitian ini dilakukan melalui memfokuskan isu yang memiliki potensi besar untuk dikembangkan. Jika dilihat dari beberapa isu yang ada di pilihlah isu sejarah dalam bidang kapal di Indonesia. Mengkaji antara data, literatur, dan dokumen-dokumen elektronik yang bersangkutan dengan isu yang diambil. Data yang diperoleh akan dianalisis ditahap ini sehingga dapat ditarik kesimpulan. Metode analisis data yang digunakan antara lain :

- Reduksi data

- Merangkum, memilih hal-hal yang pokok, memfokuskan pada hal-hal yang penting.

- Penyajian data

- Penyajian data dapat dilakukan dengan bentuk uraian singkat, bagan, dsb.

- Simpulan, langkah terakhir dalam analisis data kualitatif adalah penarikan kesimpulan dan verifikasi.

Metode perancangan dengan pendekatan Architourism of the Metropolis, metode yang digunakan dalam perancangan dengan melakukan pendekatan tentang Architourism of the Metropolis yang berujung pada desain dan konsep perancangan.

\section{DISKUSI DAN HASIL}

\section{Pengertian Architourism of The Metropolis}

Architourism adalah Pariwisata melibatkan melihat bangunan dan karya arsitektur. Architourism merupakan bagian dari wisata arsitektur yang secara spesifik menggunakan pendekatan kontemporer. Istilah ini pertama kali digunakan oleh Colombia University pada tahun 2002, yang terinspirasi dari fenomena The Bilbao Effect (Specht, 2014).

Metropolis sendiri secara etimologi; berasal dan bahasa Yunani, yaitu dari kata meter yang bermakna 'ibu' dan polis bermakna (1) 'ibu kota' atau 'kota terpenting dalam negara atau wilayah' dan (2) 'kota yang menjadi pusat kegiatan perdagangan industri, dan pemerintahan'. 
Definisi kawasan metropolitan yang relevan dalam konteks negara Indonesia, yaitu berdasarkan Undang-Undang Tahun 26 Tahun 2007 tentang Penataan Ruang. Undang-Undang tersebut mendefinisikan kawasan metropolitan sebagai kawasan perkotaan yang terdiri atas sebuah kawasan perkotaan yang berdiri sendiri atau kawasan perkotaan inti dengan kawasan perkotaan di sekitarnya yang saling memiliki keterkaitan fungsional yang dihubungkan dengan sistem jaringan prasarana wilayah yang terintegrasi dengan jumlah penduduk secara keseluruhan sekurang-kurangnya 1.000 .000 (satu juta) jiwa (Hermit, 2007).

\section{Jakarta sebagai Tujuan Pariwisata}

Kota Jakarta pantas menjadi satu kota yang banyak dituju dan dikunjungi berbagai elemen masyarakat dari berbagai penjuru daerah. Memiliki tingkat heterogenitas yang tinggi dan berpredikat sebagai ibu kota negara, pembangunan di Kota Jakarta memang terasa lebih pesat karena di sinilah pusat perekonomian bangsa sebagian besar dikontrol dan digerakkan dan tidak menutup kemungkinan Jakarta menjadi pusat pariwisata.Berkembangnya sektor pariwisata juga dapat mendorong pemerintah lokal untuk menyediakan infrastruktur yang lebih baik, meningkatnya perekonomian masyarakat lokal menggeliat dan menjadi stimulus berinvestasi

\section{Potensi Jakarta Utara Sebagai Tujuan Pariwisata}

1. Memiliki potensi wisata bahari Jakarta (museum bahari, galangan VOC, pasar ikan, Pelabuhan, Ancol, dII) yang dapat saling terintegrasi. Dengan adanya program pemerintah Jakarta Utara untuk merehabilitasi pariwisata di Jakarta Utara di bawah proyek 12 wisata pesisir Jakarta Utara (Indonesia: 12 jalur destinasi-Wisata Pesisir Jakarta Utara) (JU, 2017). Terlihat bahwa Jakarta Utara ingin memanfaatkan potensi pesisir laut yang dimiliki.

2. Reklamasi di pesisir Jakarta utara nantinya akan menjadikan Jakarta utara berada ditengah antara pulau-pulai hasil reklamasi dan kota Jakarta tentunya akan menjaadi wilayah yang memiliki potensi besar untuk berkembang dalam sisi ekonomi maupun infrastuktur.

3. Selain akses menuju kawasan lain yang cukup mudah dan berbatasan langsung dengan Laut Jawa di bagian utara, Bekasi di timur, Jakarta Barat, Jakarta Timur, dan Jakarta Pusat di selatan, serta Tangerang di barat.

\section{Pengaruh Perancangan terhadap Tapak}

1. Mendukung program pariwisata 12 pesisir di Jakarta Utara dengan menambah keragamanan objek wisata bahari yang telah tersedia di daerah Jakarta Utara.

2. Menjadikan kawasan penjaringan sebagai titik pariwisata sejarah bahari di Jakarta dengan menyediakan sebuah ikon baru wisata bahari berupa Museum bertemakan kapal perpanjangan dari Museum Bahari yang telah usang dan dimakan oleh waktu.

3. Sebagai satu kesatuan yang saling mendukung dengan wisata bersejarah pelabuhan sunda kelapa yang identik dengan kapal pinisi dengan menyediakan wadah untuk menambah wawasan mengenai sejarah kapal. 


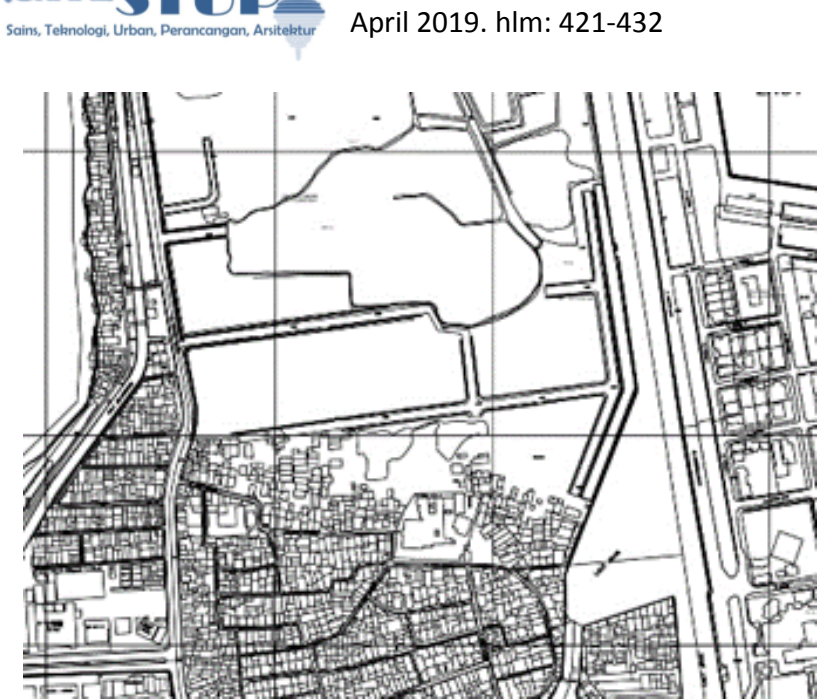

\section{Gambar 1. Lokasi Tapak}

Sumber: dokumen pribadi, 2018

Lokasi tapak berada di jalan Muara Baru Raya, kelurahan Penjaringan, kecamatan Penjaringan, Jakarta Utara. Tapak memiliki luas $1.35 \mathrm{Ha}$. Disekeliling tapak berbatasan dengan : Utara (Apartemen Pluit Sea View), Barat (Pergudangan 1-2 lantai), Timur (Pelabuhan Sunda Kelapa) dan Selatan (Hunian 1-2 lantai).

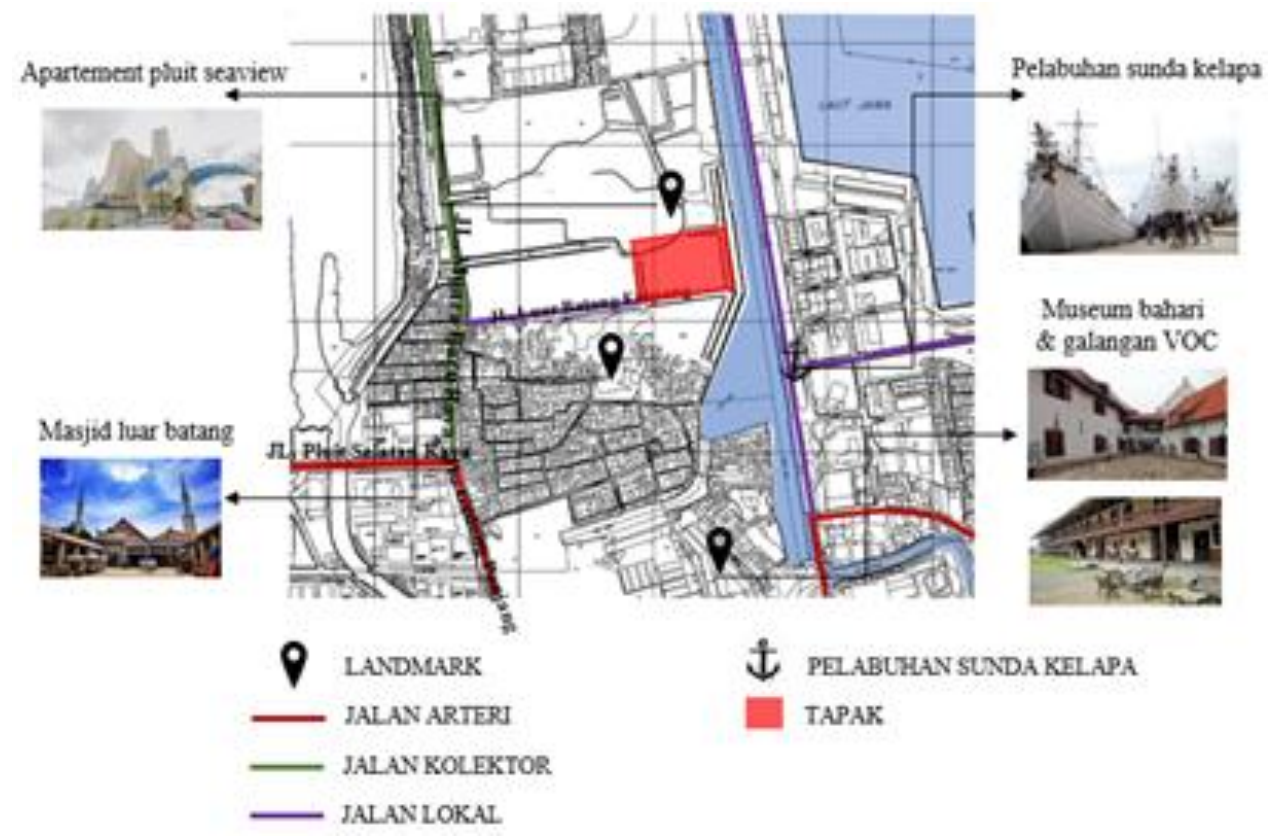

Gambar 2. Tapak Terhadap Sekitar Sumber: dokumen pribadi, 2018

Akses jalan utama tapak berada pada JL. Muara Baru Raya (2 lajur). Jalan arteri terdekat adalah JL. Pluit Selatan Raya, JL. Gedong panjang yang terletak $+560 \mathrm{~m}$ dari tapak dan $+240 \mathrm{~m}$ dari jalan akses masuk tapak yaitu JL Muara Baru Raya. Kondisi jalan sekitar tapak cukup baik namun jalur pedestrian pada area ini belum tertata. 
Konsep Perancangan

Program Aktifitas

Tabel 1. Program Kegiatan Bangunan

\begin{tabular}{|c|c|c|}
\hline Nama ruang & Program & Kegiatan \\
\hline Ruang pamer & utama & Melihat benda-benda yang di pamerkan \\
\hline Area audiovisual & utama & Mencoba permainan berbasis audiovisual \\
\hline Area simulator & utama & $\begin{array}{l}\text { Mencoba simulator berhubungan dengan } \\
\text { navigasi kapal \&perahu }\end{array}$ \\
\hline Cinema $4 D$ & utama & $\begin{array}{l}\text { Menyaksikan film berhubungan dengan sejarah } \\
\text { maritim indonesia }\end{array}$ \\
\hline Aquarium & utama & $\begin{array}{l}\text { Belajar terkait ikan pada kedalaman terumbu } \\
\text { karang }\end{array}$ \\
\hline Outdoor activity & utama & $\begin{array}{l}\text { Mencoba mendayung perahu kano, perahu } \\
\text { pedal, dan remote control racing }\end{array}$ \\
\hline crafting & pendukung & $\begin{array}{l}\text { Membuat miniatur kapal pinisi, alat tangkap } \\
\text { ikan sederhana }\end{array}$ \\
\hline Ruang auditorium & pendukung & Melakukan kegiatan seminar \\
\hline Ruang serbaguna & pendukung & Dapat digunakan untuk berbagai kegiatan \\
\hline e-library & pendukung & Mencari informasi kapal dengan sistem digital \\
\hline Toko souvenir & pendukung & membeli souvenir \\
\hline Restoran & pendukung & Makan dan minum \\
\hline
\end{tabular}

Kebutuhan luasan total Museum Kapal Nusantara si Jakarta Utara adalah sebagai berikut :

Tabel 2. Total Luasan Program Kegiatan Bangunan

\begin{tabular}{|l|c|}
\hline \multicolumn{1}{|c|}{ Kegiatan } & Luasan \\
\hline Kegiatan utama \& pendukung & $8,616.8 \mathrm{~m} 2$ \\
\hline Kegiatan pengelola & $543,44 \mathrm{~m} 2$ \\
\hline Kegiatan servis dan parkir & $5,058.3 \mathrm{~m} 2$ \\
\hline Total & $11,361 \mathrm{~m} 2$ \\
\hline
\end{tabular}

Sumber: dokumentasi pribadi, 2018.

\section{Konsep Zonasi Massa Bangunan}

Orientasi utama bangunan menghadap pada pelabuhan sunda kelapa sehingga bangunan terlihat sebagai satu kesatuan dengan pelabuhan sunda kelapa dan tentunya untuk kepentingan view utama bangunan. Outdoor activity diletakan pada bagian yang bersinggungan dengan pelabuhan sunda kelapa sehingga pengunjung yang sedang menikmati aktivitas yang disediakan pada outdoor activity disuguhkan view langsung pelabuhan sunda kelapa dan terlihat menyatu dan menarik jika dilihat dari museum bahari sehingga membuat orang tertarik untuk datang ke museum ini (lihat gambar 3 dan gambar 4)

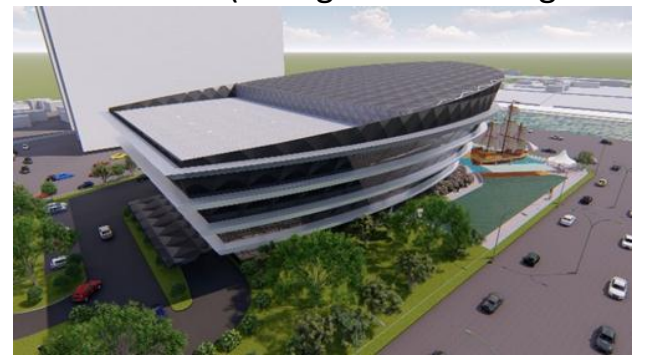

Gambar 3. Perspektif Eksterior Bangunan

Sumber: dokumen pribadi, 2018 


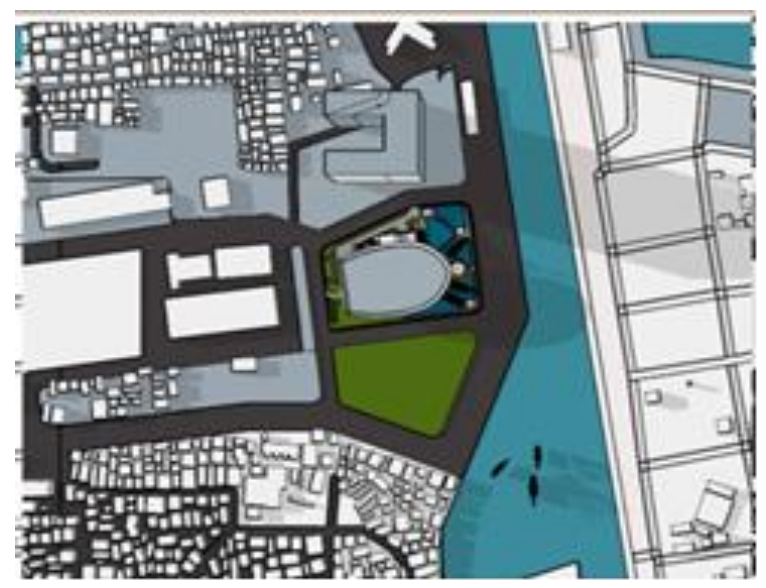

Gambar 4. Blockplan Bangunan

Sumber: dokumen pribadi, 2018

Zoning program utama yaitu ruang pamer diletakan menghadap pelabuhan sunda kelapa sebagai orientasi view utama. Pada lantai 1 diletakan koleksi kapal-kapal replika yang berukuran besar sehingga pengunjung disambut dengan kemegahan kapal-kapal Nusantara. Persebaran program bangunan disetiap lantai adalah sebagai berikut:

- Program utama : $56 \%$ (outdoor activity)

- Museum (It 1-2), audiovisual (It. 2), aquarium (It. 1), outdoor activity (It. 1), area simulator (It. 3), cinema (It. 3).

- Program pendukung : $31,2 \%$

- Crafting (It. 1), E-library (It. 1), restoran (It. 1), ruang seminar (It. 4), ruang serbaguna (It. 4), area pamer temporer (It. 4), toko souvenir (It. 1).

- Servis \& pengelola (It basement \& It 1- It 2) : 12,8 \%(lihat gambar 5)

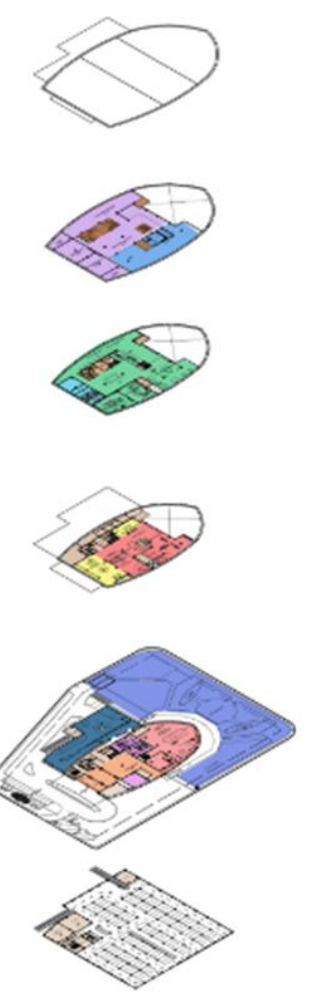

Gambar 5. Zoning Bangunan

Sumber: dokumen pribadi, 2018 


\section{Konsep Rancangan Proyek}

Bentuk massa bangunan terinspirasi oleh bentuk kapal layar tradisional yang memiliki bentuk khas lengkungan pada bagian sehingga bentuk massa mencerminkan identitas bangunan yang merupakan museum kapal, tentunya dengan mengambil bentuk kapal membangkitkan collective memory orang yang melihatnya dan langsung terbersit pada pikiran yang melihatnya bahwa bentuk bangunan menyerupai kapal yang juga membuat bentuk massa bangunan mencerminkan isi dalam bangunan yang memberi identitas bangunan itu sendiri dilihat dari luar (lihat gambar 6)

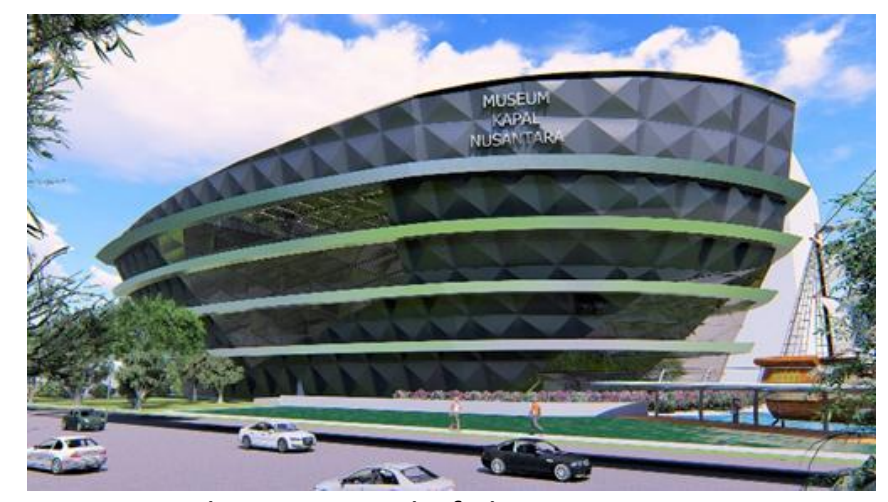

Gambar 6. Perspektif Eksterior Bangunan

Sumber: dokumen pribadi, 2018

Bagian penghijauan utama diletakan dibelakang yang berfungsi untuk jalur khusus pedestrian, juga merupakan arah mata angin barat sehingga dibutuhkan banyak pembayangan untuk mengurahi panas matahari (lihat gambar 3). Fasad berupa panel ACP berwarna abu-abu sehingga bangunan terlihat mencolok dibandingkan bangunan sekitarnya sehingga tentunya bangunan terlihat unik dan ikonik diantara sekitarnya(lihat gambar 6). Penggunaan kaca yang besar merupakan kebutuhan dari barang pajang museum yaitu kapal tradisional yang berbahan kayu sehingga tidak berjamur. Selain itu penggunaan bidang kaca yang lebar pada bagian depan bangunan yang didalam nya merupakan ruang pamer yang merupakan program utama dilakukan agar ketika pengunjung masuk ruang pamer akan disambut oleh koleksi replika kapal Nusantara dengan skala besar yang mengarah langsung pada outdoor activity dan pelabuhan sunda kelapa (lihat gambar 7)

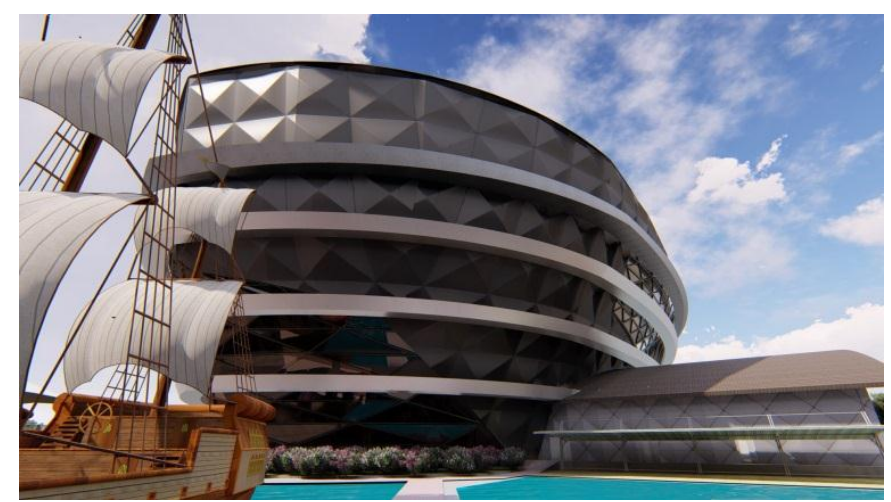

Gambar 7. Zoning Bangunan

Sumber: dokumen pribadi, 2018

Bagian dalam ruangan menggunakan elemen bernuansa kayu baik plafon, lantai maupun dinding. Dimaksudkan agar interior bangunan menggambarkan interior dalam pada kapal tradisional yang masih menggunakan kayu secara keseluruhan (lihat gambar 8 dan 9). 


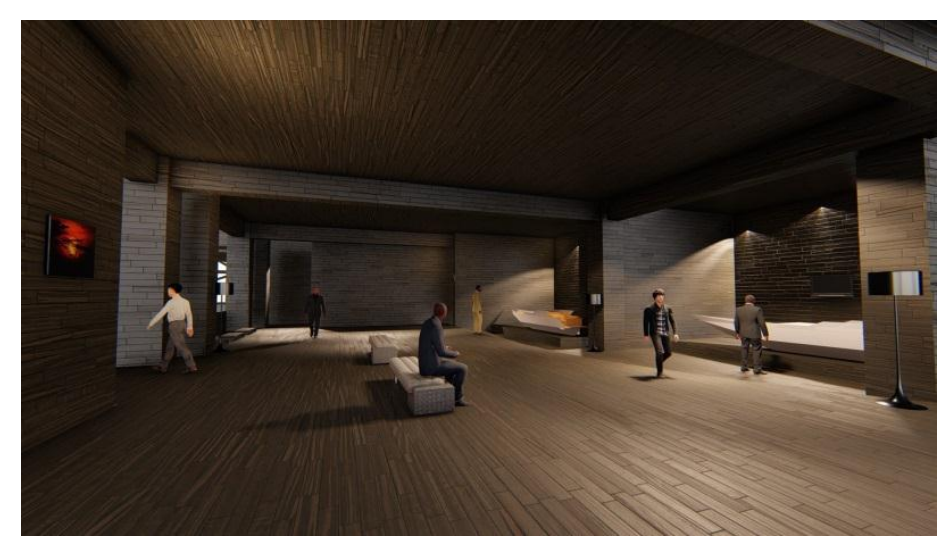

Gambar 8. Perspektif Interior Bangunan Sumber: dokumen pribadi, 2018

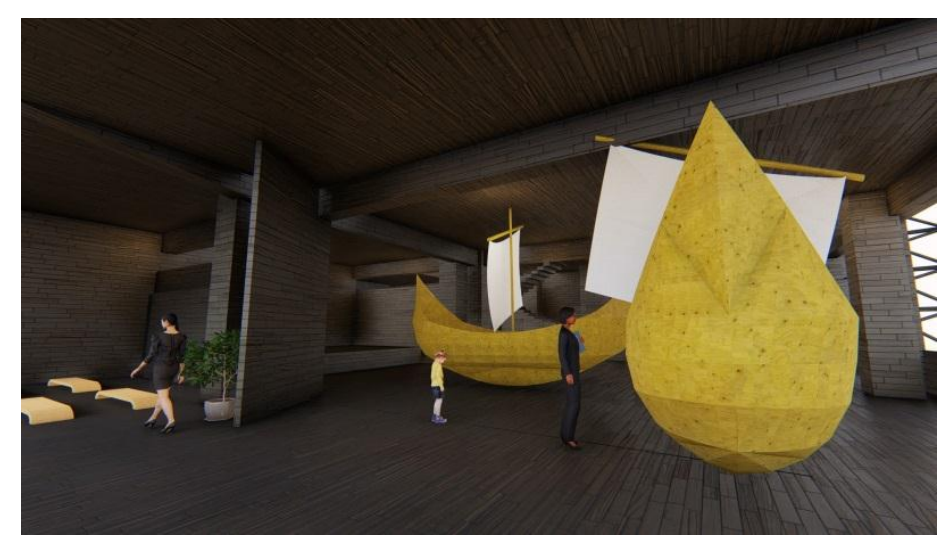

Gambar 9. Perspektif Interior Bangunan

Sumber: dokumen pribadi, 2018

Ketinggian perlantai 5-6 meter sehingga bangunan berkesan megah dan luas yang menggambarkan kejaayan bahari negara Indonesia tempo dulu (lihat gambar 10)

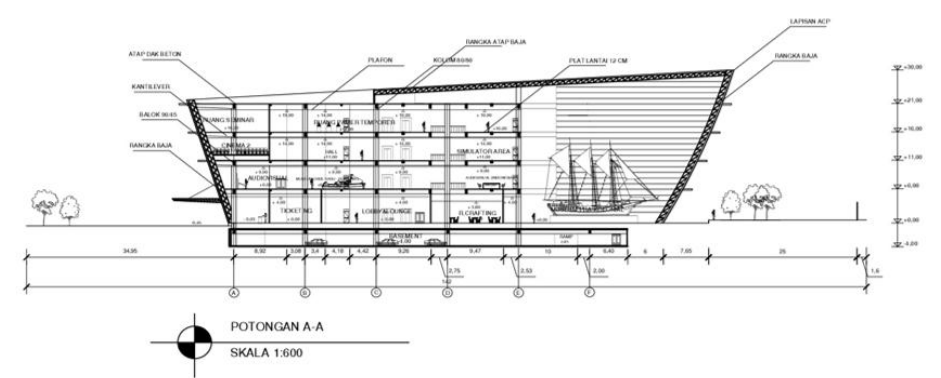

Gambar 10. Potongan Bangunan

Sumber: dokumen pribadi, 2018

Akses masuk kedalam tapak dipisah antara pengguna kendaraan bermotor dan penjalan kaki, kedua akses ini dipisah oleh penghijauan. Akses masuk kendaraan bermotor terletak dibagian barat, menuju drop off atau bisa langsung menuju parkir ground, disediakan juga parkir basement pada tapak yang pintu masuk nya berada di bagian utara menempel pada massa bangunan. Untuk parkir bis disediakan parkir khusus di ground dan untuk keperluan servis loading dock disediakan parkir ground khusus disamping massa bangunan dibagian utara. Untuk pintu keluar kendaraan bermotor dari tapak terletak dibagian utara tapak, pintu keluar basement juga terletak dibagian utara dekat dengan pintu keluar tapak (gambar 11). 


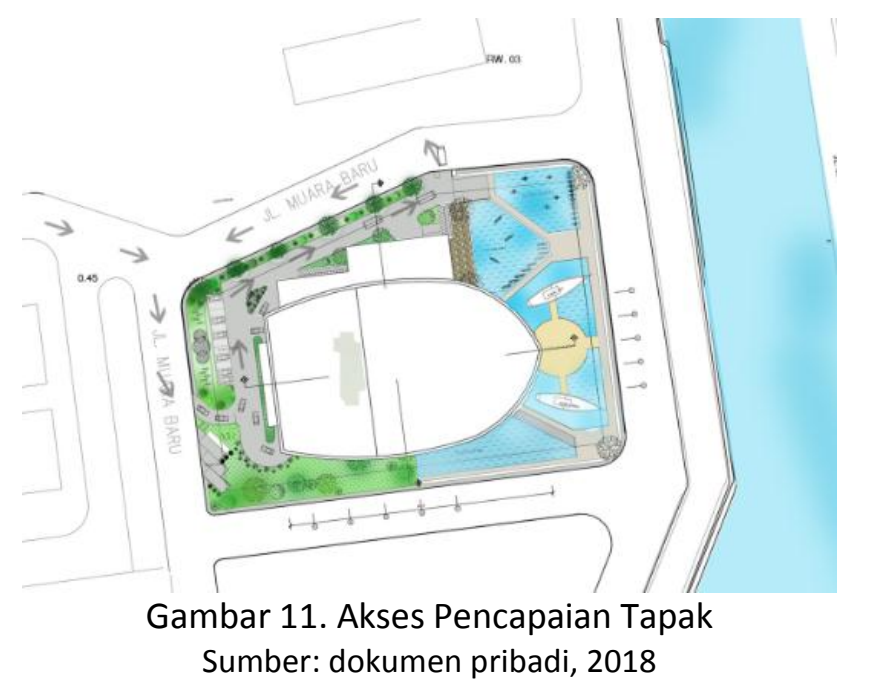

\section{Hasil Rancangan Proyek}

Museum Kapal Nusantara di Jakarta Utara merupakan proyek tugas akhir yang diharapkan dapat menjadi sarana rekreasi yang edukatif mengenai kapal nusantara yang mengangkat sejarah besar bahari Indonesia sebagai daya tarik bagi pengunjung.

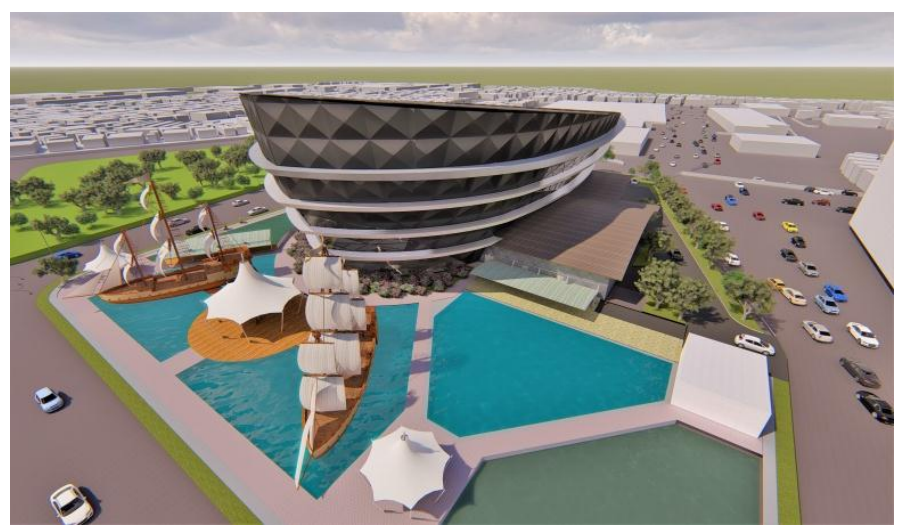

Gambar 12. Potongan Bangunan

Sumber: dokumen pribadi, 2018

Berdasarkan studi Architourism of The Metropolis, hasil analisis data dan konsep perancangan proyek terhadap zona tapak dan massa bangunan diperoleh desain perancangan proyek sebagai berikut:

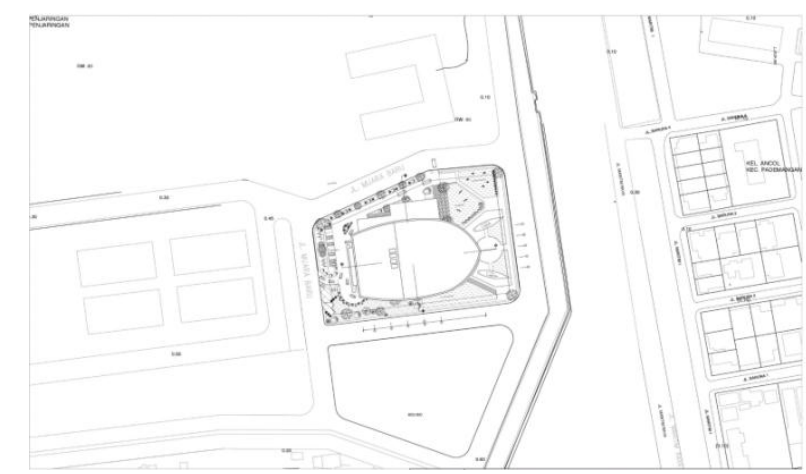

Gambar 13. Block Plan Bangunan

Sumber: dokumen pribadi, 2018 


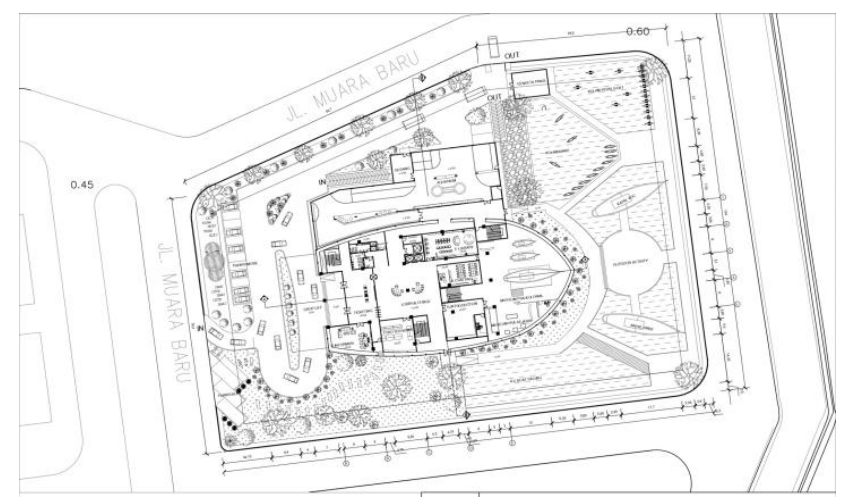

Gambar 14. Site Plan Bangunan

Sumber: dokumen pribadi, 2018

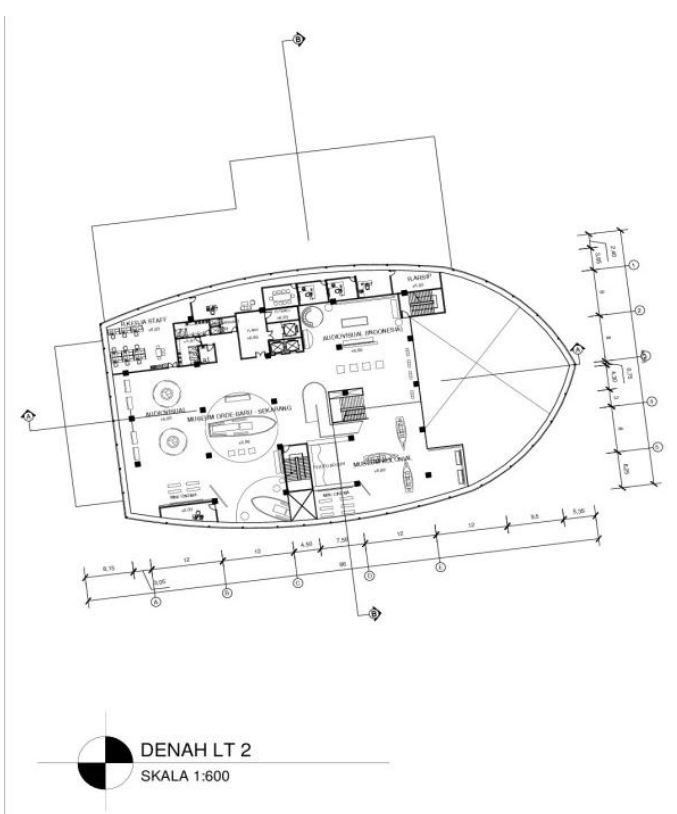

Gambar 15. Denah Lantai 2 Bangunan

Sumber: dokumen pribadi, 2018

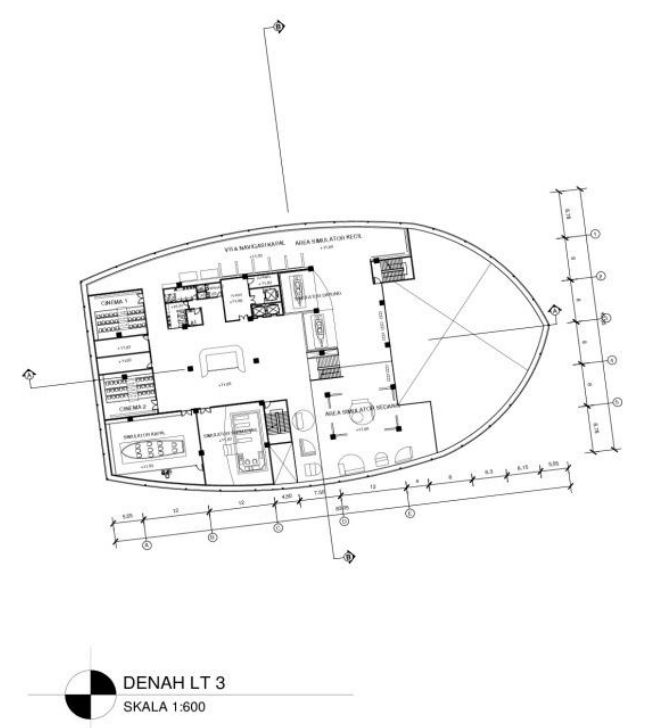

Gambar 16. Denah Lantai 3 Bangunan

Sumber: dokumen pribadi, 2018 


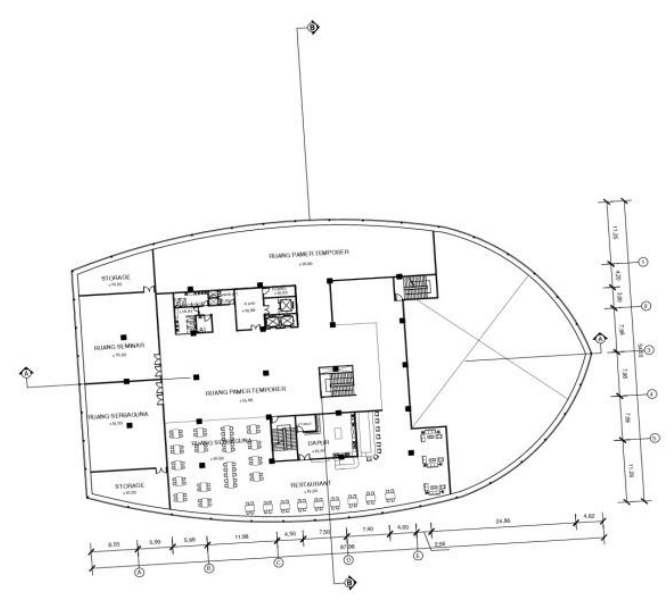

DENAHLT 4

SKALA 1:600

Gambar 17. Denah Lantai 4 Bangunan

Sumber: dokumen pribadi, 2018
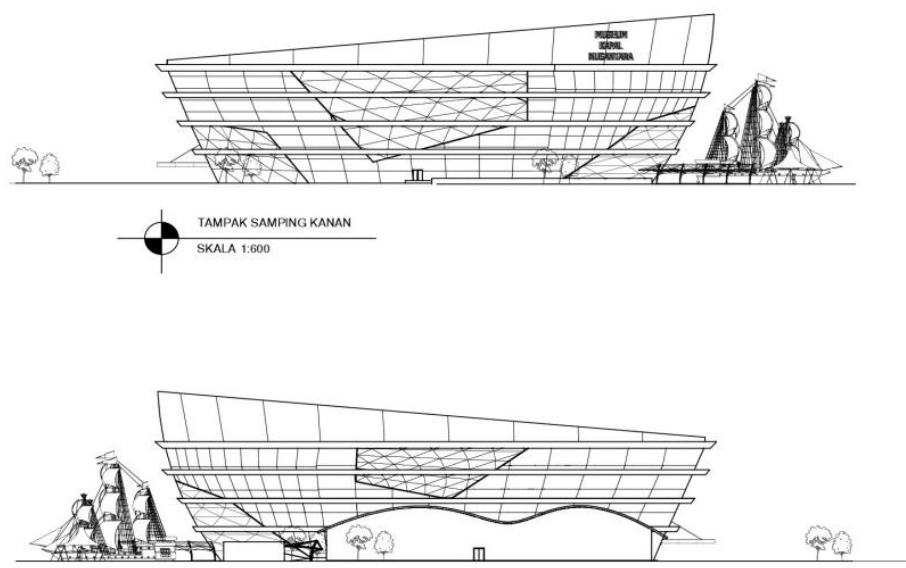

TAMPAK SAMPING KIPI

SKALA 1:600

Gambar 18. Tampak Samping Bangunan

Sumber: dokumen pribadi, 2018
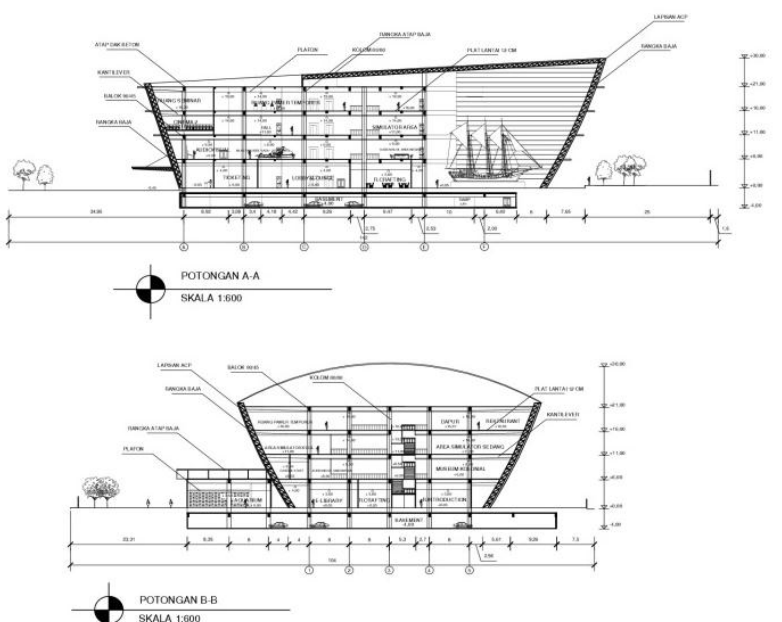

Gambar 19. Potongan Bangunan

Sumber: dokumen pribadi, 2018 


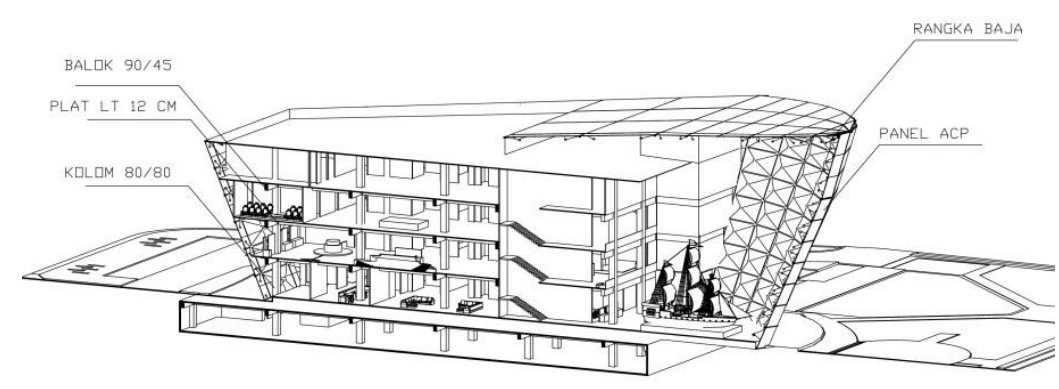

Gambar 20. Potongan Perspektif Bangunan Sumber: dokumen pribadi, 2018

\section{KESIMPULAN DAN SARAN}

Sejarah mempunyai nilai penting yang harus terus dilestarikan. Setiap hal di dunia ini memiliki sejarah nya masing-masing. Keberadaan fasilitas yang menyajikan informasi sejarah kapal Nusantara dapat meningkatkan nilai tambah Jakarta Utara sebagai tujuan wisata bahari yang edukatif di Jakarta. Dimana dapat mempermudah masyarakat Indonesia untuk mendapat informasi lengkap mengenai sejarah perkapalan Indonesia. dengan penyajian informasi yang dibungkus dan berbagai program menarik lain yang disediakan dapat meningkatkan ketertarikan masyarakat Indonesia untuk mempelajari dan memahami salah satu bagian dari warisan budaya bahari yaitu sejarah dan budaya perkapalan Indonesia.

\section{UCAPAN TERIMA KASIH}

Perkenankan pada kesempatan kali ini penulis mengucapkan terima kasih serta Puji dan syukur kepada Tuhan Yang Maha Esa atas segala rahmat dan berkat yang telah diberikan Nya, Orang tua dan yang telah memberi banyak dukungan kepada penulis secara moril maupun materil hingga jurnal ilmiah ini dapat selesai.

\section{REFERENSI}

Hermit, H. (2007). Pembahasan Undang-Undang Penataan Ruang (U.U. No. 26 Tahun 2007). Jakarta: Mandar Maju.

JU, K. (2017). Berita. Retrieved from utara.jakarta.go.id: http://utara.jakarta.go.id. Diakses tanggal 22 Maret 2017.

Motik, C. (2007). Kekayaan Negeriku Negara Maritim. Jakarta: Sekertariat Dewan Maritim Indonesia.

Specht, J. (2014). Architectural Tourism: Building for Urban Travel Destination. Wiesbaden:

Gabler Verlag.

Artikel Internet:

https://jakartasatu.jakarta.go.id ; diakses tanggal 27 Agustus 2018 pukul 14:24

https://jakartasatu.jakarta.go.id/pkrdtr/ ; diakses tanggal 27 Agustus 2018 pukul 16:08 